\title{
Las denuncias ciudadanas sobre cumplimiento ambiental en América del Norte (1996-2012): perspectivas sobre la sociedad civil ambientalista norteamericana
}

\author{
RaÚl Pacheco-VegA *
}

\section{RESUMEN}

Las denuncias ciudadanas sobre cumplimiento ambiental de la Comisión para la Cooperación Ambiental de América del Norte (CCAAN) son un mecanismo no vinculante utilizado por la sociedad civil para denunciar ante esta comisión el incumplimiento de la legislación ambiental de Estados Unidos, Canadá y México. Utilizando una base de datos de denuncias ciudadanas (1996-2012), este artículo ofrece una evaluación del mecanismo en tres áreas: a) influencia perceptible sobre los gobiernos nacionales norteamericanos; $b$ ) desempeño e influencia en escalas subnacionales, y c) patrones de evolución histórica.

Palabras clave: Norteamérica, política ambiental, política pública comparada, denuncias ciudadanas, cumplimiento ambiental.

\section{ABSTRACT}

A citizen complaint presented to the Commission for Environmental Cooperation (CEC) of North America is a non-binding mechanism used by civil society to denounce incompliance with U.S., Canadian, and Mexican environmental legislation. Using a data base of citizens' complaints (1996-2012), this article offers an evaluation of the mechanism in three areas: $a$ ) perceptible influence on the three North American governments; $b$ ) performance and influence on subnational levels; and c) patterns of historic evolution.

Key words: North America, environmental policy, compared public policy, citizen complaints, environmental compliance.

* Profesor de la División de Administración Pública, Centro de Investigacion y Docencia Económicas, Región Centro, raul.pacheco-vega@cide.edu 


\section{INTRODUCCIÓN}

El Tratado de Libre Comercio de América del Norte (TLCAN), firmado en 1994, fue uno de los tratados parteaguas en décadas recientes, pues estableció efectivamente una zona de libre comercio entre los tres países de Norteamérica (Canadá, Estados Unidos y México). Hasta antes de la firma del TLCAN, la frase "América del Norte" conjuraba únicamente los nombres de los países anglosajones norteamericanos (Canadá y Estados Unidos). Al establecer la zona de libre comercio de América del Norte, el tratado empezó (si bien de forma vacilante y en algunos casos, con bastantes raspones en el trayecto) a construir una región norteamericana (Kirton, 2002; Knox, 2004). Al mismo tiempo de la firma del TLCAN, hubo negociaciones en materia laboral (Nolan García, 2011) y ambiental (Pacheco-Vega et al., 2001) que establecieron dos acuerdos marco colaterales al tratado de libre comercio, uno sobre trabajo y derechos laborales (North American Agreement on Labor Cooperation, NAALC por sus siglas en inglés, y el North American Agreement on Environmental Cooperation, NAAEC). En ambos casos, los tratados tienen una secretaría general (Secretariat), en el caso del tratado ambiental denominada Comisión para la Cooperación Ambiental en América del Norte (CCAAN).

Las denuncias ciudadanas sobre cumplimiento ambiental de la CCAAN son un mecanismo utilizado por la sociedad civil para denunciar el incumplimiento de su legislación ambiental por parte de los gobiernos de Estados Unidos, Canadá y México (Canada/U.S. / Mexico, 1993). El mecanismo tiene como objetivo ofrecer a los ciudadanos un foro gracias al cual es posible presionar a los gobiernos nacionales para verificar que estén cumpliendo con la legislación ambiental. Dicho proceso venía de la mano de los mecanismos de resolución de controversias en el TLCAN y ha sido motivo de amplia discusión en los ámbitos académicos en que se estudia a América del Norte (Borrego et al., 2007; Borrego Pérez, 2006).

A pesar de que el diseño del mecanismo de denuncia ciudadana no tiene una naturaleza vinculante, y se motiva el cumplimiento ambiental sólo en la escala nacional, un buen número de coaliciones transnacionales han usado el mecanismo para presionar a industrias contaminantes, así como a gobiernos subnacionales en algunos casos (Pacheco y Dowlatabadi, 2005; Pacheco-Vega, 2005). Como explica Blanca Torres, el interés de las organizaciones no gubernamentales ambientalistas (ONGA) sobre México se origina en gran parte en en el hecho de que nuestro país y Estados Unidos comparten una frontera (Torres, 1999; 2005), y por lo mismo, los daños ambientales que se generan en dicha zona fronteriza pueden derramarse a ambos lados, por lo cual es de vital importancia que se enfoquen en resolver dichos problemas de manera coordinada. Las organizaciones ambientalistas de la sociedad civil, por ende, tienen 
un papel no solamente de "vigilante" (watchdog) sino, en ocasiones, de informador y proveedor de datos para la toma de decisiones consensadas con los gobiernos.

El análisis del uso tan diverso del mecanismo de denuncias de la CCAAN permite explorar una variedad de comportamientos en materia de política ambiental tanto por parte de los países de América del Norte como de los denunciantes y de los agentes objeto de la denuncia. El número de denuncias ciudadanas ha crecido suficientemente (a un total de ochentaiún denuncias en total, con once denuncias activas), de suerte que es posible ahora hacer análisis más robustos en una base de datos más completa, abarcando un total de diecisiete años.

Este artículo ofrece una contribución empírica más que teórica, ya que tanto los datos presentados como el análisis son originales. Los estudios teóricos previos que se han realizado en materia de denuncia ciudadana sobre cumplimiento ambiental se han enfocado en las diferentes estrategias de su utilización como una "alarma contra fuego" o como "patrulla de policía" (Raustiala, 2004), en el contexto de su legitimidad como instrumento de política (Knox y Markell, 2012), en su incapacidad para mitigar la falta de cumplimiento de la legislación ambiental (Lewis, 2007; Yang, 2005), en su utilización como mecanismo supranacional para influir en la operación de las políticas ambientales internas (Longiaru, 2008; Wilson, 2005) y en su papel como instrumentos de "ley suave" (soft law) (Graubart, 2005; 2009). El contexto teórico sobre el cual se fundamenta el presente artículo está en la literatura presentada en las secciones posteriores del documento, primordialmente en las hipótesis de utilización del mecanismo como herramienta para "avergonzar" a los gobiernos de Canadá, Estados Unidos y México, muy en el estilo del mecanismo de transmisión de la presión de segundo orden de Pacheco-Vega o en el boomerang de Keck y Sikkink (Pacheco-Vega, 2005). Específicamente, los datos presentados en este artículo permiten establecer y corroborar (o descartar) hipótesis sobre la utilización del mecanismo.

Utilizando una base de datos propia construida aparte de la lista de denuncias ciudadanas sobre cumplimiento ambiental (1996-2012) de la CCAAN, este artículo ofrece una perspectiva analítica del mecanismo en tres áreas: $a$ ) influencia perceptible sobre los gobiernos nacionales norteamericanos; $b$ ) desempeño e influencia en escalas subnacionales y c) patrones de evolución histórica de la política ambiental en América del Norte. El artículo presenta evidencia empírica sobre la evolución de la denuncia ciudadana como instrumento de política ambiental norteamericana, y examina los alcances, limitaciones y perspectivas a futuro de desarrollo del mismo. En específico, una hipótesis que amerita análisis es que la creciente relevancia de las cortes en los países de América del Norte ha orillado a las organizaciones de la sociedad civil a tomar menos acciones mediante el mecanismo de las peticiones ciudadanas y más mediante mecanismos nacionales y subnacionales. Ello nos lleva a pensar que en los 
países con sistemas judiciales más robustos, el mecanismo de denuncia ciudadana será utilizado con menor frecuencia. La evidencia empírica presentada en este artículo proporciona confirmación al menos parcial a esta hipótesis, si bien deja abierta la pregunta de por qué se deja de utilizar contra Canadá, una pregunta de investigación que amerita un documento subsecuente.

\section{LAS DENUNCIAS CIUDADANAS SOBRE CUMPLIMIENTO AMBIENTAL EN NoRTEAMÉRICA: UNA PERSPECTIVA HISTÓRICA}

Si bien todavía no se puede hablar de que exista un régimen de política ambiental norteamericano, la convergencia de políticas públicas ambientales en América del Norte ha sido uno de los temas fundamentales de discusión al centro de los estudios académicos sobre Norteamérica. Uno de los mecanismos más discutidos (pero en realidad, poco analizado de manera empírica) ha sido el proceso de las citizen submissions on enforcement matters (denuncias ciudadanas sobre cumplimiento ambiental) de la CCAAN (Blair, 2003; Osofsky, 2006). La mayor parte de los estudios sobre el mecanismo de denuncias ciudadanas ha sido descriptivo (Markell, 2005), crítico de su diseño y estructura legal y funcional (Lewis, 2007; Wold, 2004), o en los pocos casos analíticos, enfocados primordialmente en casos específicos de estudio (Powell, 2000; Stanton Kibel, 2001; Yang, 2005). Una excepción a la regla ha sido el trabajo de Pacheco-Vega, Weibust y Fox donde hacen un estudio longitudinal de las denuncias, centrándose en las estrategias de las ONGA y el desempeño de las mismas en cuanto al uso del mecanismo (Pacheco-Vega et al., 2010).

El establecimiento de un mecanismo de tipo whistleblower ${ }^{1}$ fue uno de los requisitos que pusieron las ONGA estadunidenses ante la firma del TLCAN (Gifuni, 2011; Torres, 2002). Así fue como nacieron las denuncias ciudadanas sobre cumplimiento ambiental. Actualmente hay diez peticiones oficialmente en proceso de un total de ochentaiún denuncias presentadas en el periodo 1995-2013. En el año 2013 no se ha presentado ninguna denuncia.

\footnotetext{
${ }^{1}$ Whistleblower se traduce al español como soplón. Es una palabra que tiene diversas acepciones en el idioma inglés, pero en el caso del mecanismo de denuncias ciudadanas, se refiere a aquellos individuos que presentan un reclamo por escrito en contra de un país.
} 


\section{UNA BREVE REVISIÓN DE LA LITERATURA TEÓRICA: EL CONTEXTO METODOLÓGICO DE ANÁLISIS DE LAS DENUNCIAS CIUDADANAS SOBRE CUMPLIMIENTO AMBIENTAL EN NORTEAMÉRICA}

Teóricamente, las denuncias ciudadanas pueden verse como una aplicación del modelo del efecto boomerang (a la Keck y Sikkink), como una herramienta para "avergonzar" al país objetivo (Anaya, 2009a; 2009b; 2011), como un componente de un sistema institucional de revisión o de implementación de un tratado, de su cumplimiento o de su efectividad (Raustiala, 2004), como un esquema de presión suave, no vinculante, o "sin dientes" (Lewis, 2007). Pero la gran realidad de las denuncias ciudadanas es que, contra lo que se pudiera pensar, han servido para fortalecer los lazos de colaboración transnacionales entre organizaciones de la sociedad civil en América del Norte. Por ejemplo, como demuestran Pacheco-Vega, Fox y Weibust, algunas peticiones han sido iniciadas por organizaciones que no pertenecen al país destino. Asimismo, ha habido instancias en las cuales una coalición binacional presenta una petición ciudadana. Así, ha habido denuncias presentadas contra Estados Unidos desde Canadá y viceversa; más aun, ha habido denuncias contra varios países en un solo proceso. En la petición SEM-06-002, Devils Lake, una coalición formada por las ONGA Friends of Earth Canada y Estados Unidos, así como People to Save the Sheyenne River, y tres individuos particulares de Dakota del Norte (Estados Unidos) y Manitoba (Canadá) presentaron una denuncia simultánea contra Estados Unidos y Canadá.

Metodológicamente, el presente trabajo fundamenta su análisis en un proceso inductivo para construir teoría a partir del análisis de los datos empíricos, en lugar de un proceso deductivo en el cual se preestablece la posición teórica de los autores y se deduce si los datos presentados confirman la teoría propuesta o no. Sin embargo, la corriente teórica que más informa sobre los resultados de este análisis es aquella que postula que las denuncias ciudadanas son un mecanismo de presión de segundo orden (Pacheco-Vega, 2005) a falta de una mejor respuesta por parte de los países destino como postulan Pacheco-Vega, Weibust y Fox (Pacheco-Vega et al., 2010). En estos enfoques teóricos, una organización de la sociedad civil dejaría de presentar denuncias mediante el mecanismo de la petición ciudadana confrontada con dos escenarios principales: el primero, en donde la efectividad de los mecanismos internos de cumplimiento ambiental son más potentes (como podría ser el caso del sistema judicial de Estados Unidos), o el segundo, en donde la efectividad de utilizar un mecanismo institucional transnacional resulta demasiado oneroso. La evidencia empírica presentada en este artículo parece apuntar a que el caso de la reducción de denuncias contra Canadá es resultado del efecto del segundo escenario, mientras que la reducción de denuncias contra Estados Unidos es resultado del primer escenario. 
El mecanismo de las peticiones ciudadanas ha sido objeto tanto de estudio como de debate sobre su efectividad o inefectividad, un gran número de autores presuponen las formas en las cuales el mecanismo se puede fortalecer, pero sin fundamentar dichas mejoras sugeridas en un análisis empírico. Por el contrario, la gran mayoría de los estudios publicados sobre las denuncias ciudadanas en materia de cumplimiento de legislación ambiental en América del Norte son de tipo legalista y teórico, en donde se presentan experimentos de pensamiento (thought experiments) en forma de propuestas que presuponen, en primer lugar, que el Secretariado de la CCAAN tiene el poder ejecutivo para implementar los cambios, y en segundo lugar, que los países norteamericanos tienen la voluntad política para implementarlos. Sin embargo, como han mencionado tanto Wold (2008) como Tollefson (2002), para que este tipo de transformaciones sugeridas se implementen, uno de los cambios más importantes que tiene que ocurrir es que Canadá, Estados Unidos y México decidan tomar al mecanismo de denuncia ciudadana como aquello para lo que estaba diseñado desde el principio: como una herramienta para fortalecer la colaboración entre los países de la región de América del Norte y sus sociedades civiles en la búsqueda de la protección del medio ambiente (Pacheco y Vega, 2003; Tollefson, 2002; Wold, 2008). Precisamente, por esta razón, decidí presentar evidencia empírica y su análisis cuantitativo, en lugar de realizar otro "experimento de pensamiento".

Históricamente, las denuncias ciudadanas ${ }^{2}$ sobre cumplimiento ambiental en América del Norte han sido utilizadas por organizaciones ambientalistas de Canadá y México primordialmente, y en segundo lugar, de Estados Unidos, como se puede apreciar en la gráfica 1.

\section{Gráfica 1}

DISTRIBUCIÓN DE DENUNCIAS CIUDADANAS SOBRE CUMPLIMIENTO AMBIENTAL (1996-2012) CLASIFICADAS POR PAÍS DENUNCIADO $(\mathrm{N}=81)$

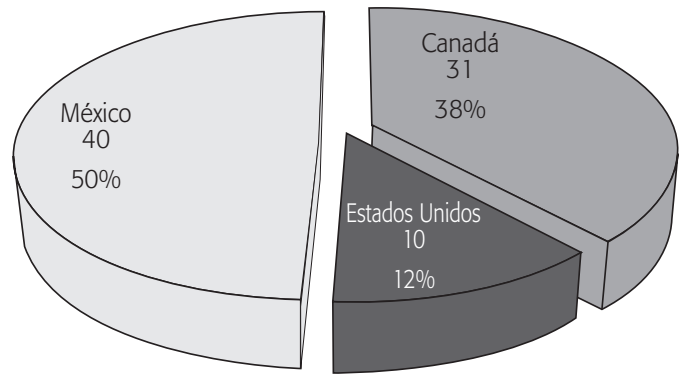

Fuente: Elaboración propia con base de datos del SEM de la CCAAN.

\footnotetext{
2 También denominadas "peticiones ciudadanas", dependiendo de la literatura.
} 
Las denuncias ciudadanas son presentadas generalmente por miembros de la sociedad civil. En la práctica, a pesar de que el diseño del mecanismo indica que es posible que cualquier ciudadano(a) presente una denuncia ante la CCAAN, solamente un grupo pequeño de organizaciones de la sociedad civil tiene realmente la capacidad instalada (tanto en recursos humanos como en experiencia legislativa y acumulación de conocimientos sobre la normativa jurídica) para presentar un expediente robusto de reclamo sobre el cumplimiento de las leyes ambientales de los países objetivo. Este elemento (la capacidad instalada y la construcción de capacidades de las organizaciones de la sociedad civil que tienen intereses ambientales) se olvida frecuentemente en las discusiones académicas, en particular en aquellos foros en los cuales se argumenta vehementemente que las organizaciones activistas pueden (y en ocasiones, en forma normativa, se les insta a que "deben de") presentar denuncias ciudadanas ante la CCAAN. El proceso de presentación de peticiones no es sencillo, gratuito ni tampoco deja de tener barreras de entrada sustanciales. Por el contrario, presentar una denuncia ciudadana conlleva el consumo de una cantidad de tiempo importante, inversión de recursos tanto materiales como humanos y el ejercicio de un grado sustancial de paciencia, ya que el proceso es lento, tardado y en ocasiones, terriblemente abrumador para organizaciones cuyo tamaño no les permite tener personal que pueda hacerse cargo de llenar y verificar todos los requisitos que establece la CCAAN para la presentación de la denuncia. La gráfica 2 muestra el procedimiento de envío de una denuncia ciudadana.

\section{UN ANÁLISIS DIACRÓNICO DE LAS DENUNCIAS CIUDADANAS SOBRE CUMPLIMIENTO AMBIENTAL EN NoRTEAmÉRICA}

El registro de una petición ciudadana ante la CCAAN conlleva para la organización ambientalista que presenta una inversión de tiempo, dinero, recursos materiales y la investigación de los detalles del caso en particular. Es también importante hacer notar que el proceso que ocurre después de la presentación de la denuncia se ha ido modificando en años recientes, se ha tratado de hacer más expedito. Sin embargo, como muestra el cuadro 1, el tiempo de procesamiento de la denuncia sigue siendo sumamente largo.

Si bien la inclusión del proceso dentro de las cláusulas del Acuerdo de Cooperación Ambiental de América del Norte fue negociada con la presión inherente de las organizaciones ambientalistas estadunidenses preocupadas por la firma del TLCAN -con lo cual uno esperaría que quienes utilizan el proceso deberían ser quienes manifestaron mayor interés en el mismo-, el análisis diacrónico presentado en esta sección 


\section{Gráfica 2}

DIAGRAMA DE FLUJO ORIGINAL DEL PROCESO DE DENUNCIAS CIUDADANAS SOBRE CUMPLIMIENTO AMBIENTAL, VÁLIDO HASTA ANTES DE JULIO DE 2012

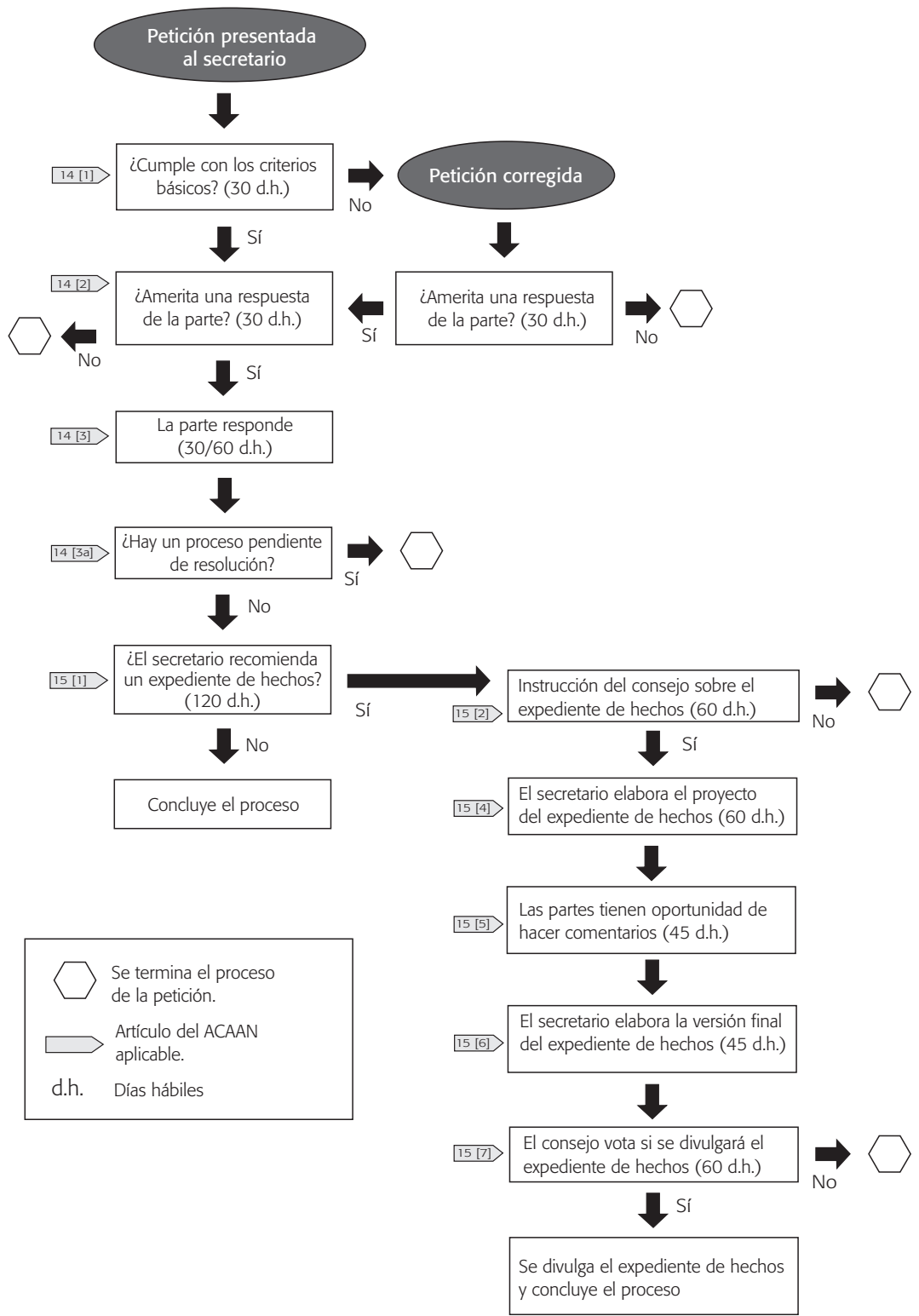

Fuente: Elaboración propia a partir del texto de los artículos 14 y 15 del CCAAN y de la imagen proporcionada en el mismo. 
y en el resto del artículo demuestra que, en realidad, ha declinado sustancialmente la participación de las ONGA en Estados Unidos en el proceso (véase la gráfica 3).

Gráfica 3

EVOLUCIÓN DEL NÚMERO TOTAL DE DENUNCIAS CIUDADANAS SOBRE CUMPLIMIENTO AMBIENTAL (1996-2012)

Total de denuncias por año

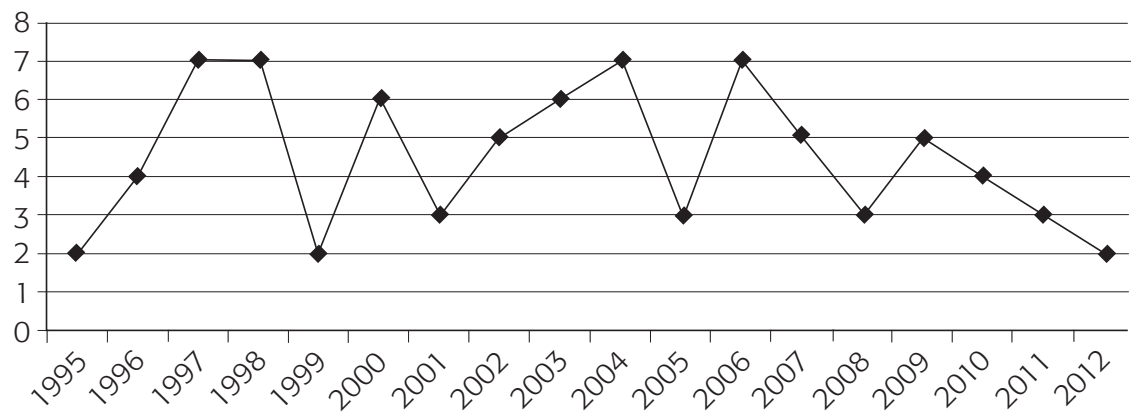

Fuente: Elaboración propia con base de datos del SEM de la CCAAN.

Como podría esperarse en el caso de países cuya legislación ambiental es considerada laxa (México, en específico), un gran número de las denuncias presentadas por ONGA ha sido en contra de México y su incumplimiento de legislación ambiental. La gráfica 4 muestra el número total de denuncias ciudadanas presentadas ante la CCAAN en el periodo 1996 a 2012 (ochentaiuna al momento de escribir este texto). Lo que resulta particularmente interesante es que (como muestra la gráfica 3), el número total de denuncias presentadas cada año ha ido disminuyendo continuamente.

\section{DENUNCIAS CIUDADANAS SOBRE CUMPLIMIENTO AMBIENTAL en América del Norte (1996-2012): UN ANÁLISIS CUANTITATIVO Y GEOGRÁFICO}

En esta sección presento el resultado de un análisis de datos cuantitativos sobre las denuncias ciudadanas en materia de cumplimiento ambiental. La distribución geográfica de estas denuncias es interesante, más allá de los aspectos escalares (Osofsky, 2006) y de gobernanza multinivel. Si bien en este artículo no realizo un estudio geoespacial detallado, sí me enfoco en estudiar las diversas áreas de influencia geográfica de cada denuncia (contrario al supuesto análisis espacial de Osofsky, 2006). 
El primer caso (Estados Unidos) es inusual, ya que como se observa en la gráfica 4, el número de denuncias ciudadanas ha ido decreciendo paulatinamente hasta terminar, y es el único país de América del Norte contra el cual no se han presentado peticiones ciudadanas por incumplimiento de la legislación ambiental en los últimos seis años.

\section{Gráfica 4}

NÚMERO DE DENUNCIAS PRESENTADAS CONTRA ESTADOS UNIDOS

$(1996-2012)(\mathrm{N}=10)$

Denuncias ciudadanas presentadas ante la CCAAN contra Estados Unidos

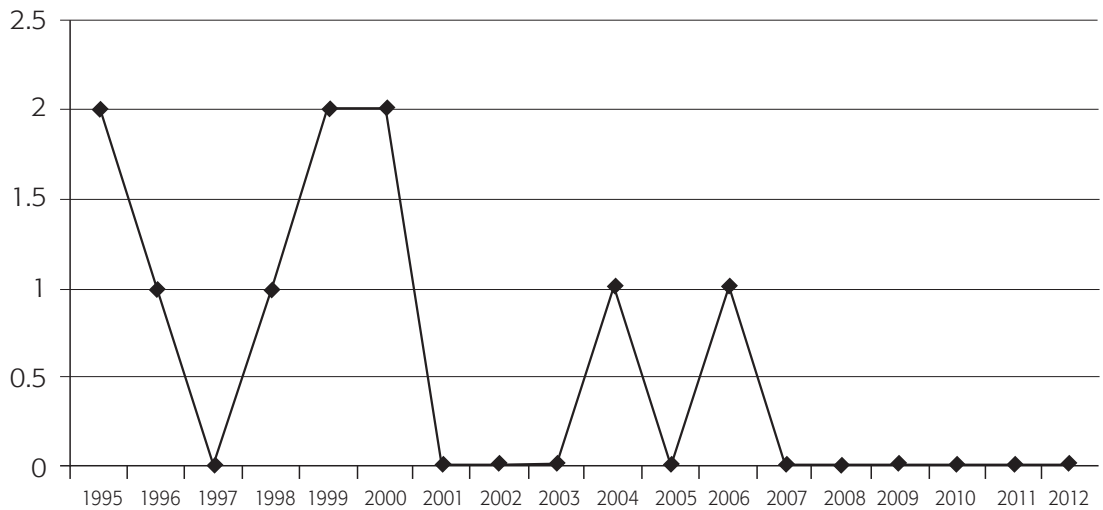

Fuente: Elaboración propia con base de datos del SEM de la CCAAN.

Las denuncias presentadas contra Estados Unidos nunca han superado las dos anuales y han venido a la baja desde 2000; a partir de 2007, la CCAAN no ha recibido más denuncias en contra de ese país. Canadá recibe en promedio 1.7 denuncias por año; en 1997 se presentó el mayor número de denuncias (cinco) en su contra, mientras que en 1999 y 2005 no recibió ninguna. México es el país que recibe más denuncias; la mayor parte de los años analizados ha tenido un número mayor o igual a dos; en 1998 recibió su mayor cantidad de denuncias por año (cinco), aunque al año siguiente en 1999 no tuvo ninguna. En los últimos años ha mostrado un cambio sustancial, pues recibió cada vez menos denuncias hasta llegar a cero en 2012.

El segundo caso, que también presenta una situación que nos deja perplejos, es el de México. Tradicionalmente, en la literatura sobre política ambiental mexicana se establece que el diseño de las leyes es adecuado, pero el cumplimiento es el que termina siendo muy pobre y, por ende, las organizaciones de la sociedad civil no tienen otro remedio más que irse a instancias superiores (en este caso, a la organización intergubernamental conocida como el Secretariado de la CCAAN). Sin embargo, como se 
puede ver en la gráfica 5, es sorprendente ver que año tras año a partir de 2009 ha venido cayendo el número de peticiones ciudadanas presentadas contra México.

Gráfica 5

NÚMERO DE DENUNCIAS PRESENTADAS CONTRA MÉXICO

$(1996-2012)(\mathrm{N}=40)$

Denuncias ciudadanas ante la CCAAN contra México (1996-2012)

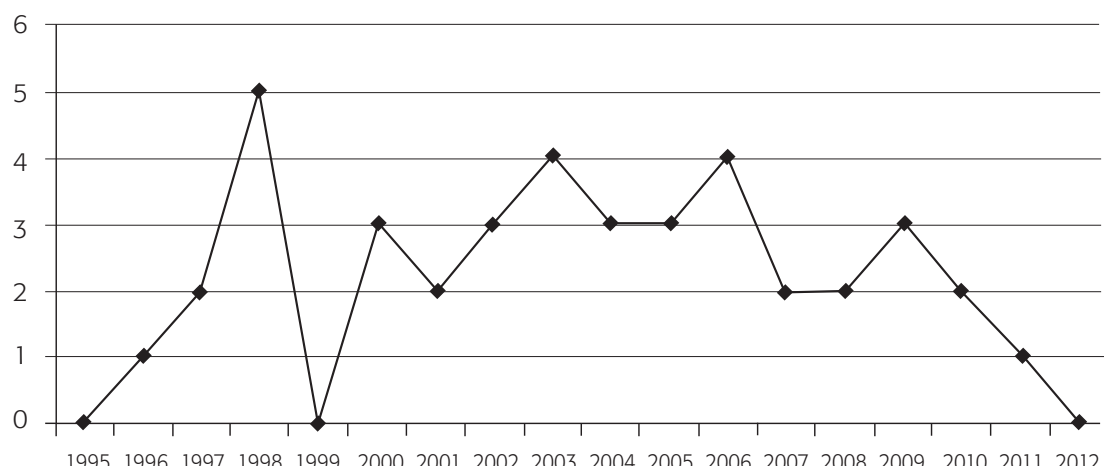

Fuente: Elaboración propia con base de datos del SEM de la CCAAN.

Considerando la popularidad que el instrumento de política tiene (la petición ciudadana sobre cumplimiento ambiental en América del Norte), resulta realmente desconcertante y difícil de entender por qué se han dejado de presentar denuncias año tras año. Ningún año (a excepción de lo que va de 2013) ha dejado de haber al menos una petición ciudadana, pero como se puede observar, a partir de 2009, el número de denuncias presentado contra México ha ido disminuyendo continuamente hasta llegar al punto en el cual no se presentó ninguna, 2012.

El tercer caso, Canadá, presenta resultados que a primera vista parecen perfectamente normales, aunque en años recientes, la tendencia de la sociedad civil ha sido presentar al menos una denuncia por año.

Es importante hacer notar que, para un análisis geográfico, es diferente delimitar cuántas denuncias fueron presentadas contra un país específico de cuántas denuncias tienen un área de influencia geográfica específica. En los gráficos 4 a 6 presenté el detalle del número de peticiones enviadas en contra de cada país de América del Norte. Sin embargo, eso no quiere decir que una denuncia enviada contra Canadá no tenga influencia en otras regiones. 


\section{Gráfica 6 \\ NÚMERO DE DENUNCIAS PRESENTADAS CONTRA CANADÁ \\ $(1996-2012)(\mathrm{N}=31)$}

Denuncias ciudadanas ante la CCAAN contra Canadá (1996-2012)

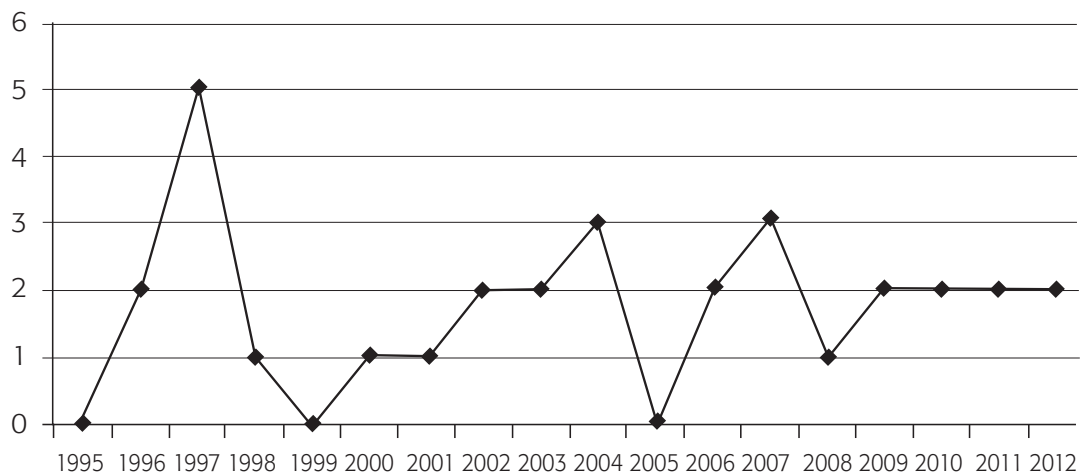

Fuente: Elaboración propia con base de datos del SEM de la CCAAN.

\section{Gráfica 7}

EVOLUCIÓN DEL NÚMERO TOTAL DE DENUNCIAS CIUDADANAS

SOBRE CUMPLIMIENTO AMBIENTAL (1996-2012) $(\mathrm{N}=81)$

Denuncias ciudadanas ante la CCAAN (1996-2012)

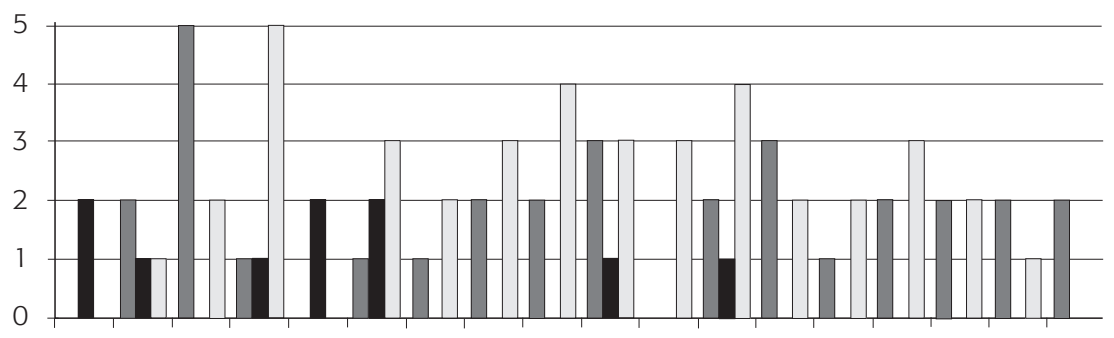

199519961997199819992000200120022003200420052006200720082009201020112012

$\square$ Canadá

—Estados Unidos $\square$ México

Fuente: Elaboración propia con base de datos del SEM de la CCAAN.

El análisis geográfico del impacto de las peticiones ciudadanas demuestra que, contra lo que pudiera pensarse, el área de impacto de una denuncia tiene un ámbito mucho mayor que si se considera únicamente el país que se denuncia. Para entender qué problemáticas son las que generan el mayor interés (estableciendo la hipótesis 
de que aquellos temas más relacionados con el impacto a la salud humana tendrán mayor atención), codifiqué las ochentaiún denuncias ciudadanas utilizando el esquema propuesto en Pacheco-Vega, Weibust y Fox (2010) clasificando las denuncias por el tipo de problema ambiental al cual se referían. Los resultados se presentan en el cuadro 1.

\section{Cuadro 1}

DENUNCIAS HECHAS DE 1996 A 2012 POR TIPO DE PROBLEMA AMBIENTAL

$\begin{array}{lcccr}\text { Problemática } & \text { México } & \text { EU } & \text { Canadá } & \text { Tota } \\ \text { Silvicultura } & 2 & 1 & 3 & 6 \\ \text { Químicos } & 14 & 2 & 6 & 22 \\ \text { Impacto ambiental } & 22 & 6 & 17 & 45 \\ \text { Aguas residuales } & 2 & 1 & 5 & 8 \\ & 40 & 10 & 31 & 81\end{array}$

Fuente: Elaboración a partir de análisis propio de base de datos creada con información disponible públicamente de la oficina del SEM de la cCAAN.

\begin{tabular}{|lll|}
\hline \multicolumn{2}{|c}{$\begin{array}{l}\text { Cuadro 2 } \\
\text { PETICIONES CIUDADANAS DE }\end{array} 996$ A 2012 EN MATERIA DE AGUAS RESIDUALES } \\
Nombre de la petición & País & Área de influencia \\
Río Magdalena & México & Sonora \\
Aquanova & México & Sonora \\
Montreal Technoparc & Canadá & Quebec \\
Devils Lake & Canadá & Canadá-Estados Unidos \\
Devils Lake & EU & Canadá-Estados Unidos \\
St. Clair River & Canadá & Ontario \\
Alberta Tailings Ponds & Canadá & Alberta \\
lona Wastewater Treatment & Canadá & Columbia Británica \\
Fuente: Elaboración a partir de análisis propio de base de datos creada con información disponible \\
públicamente de la oficina del sEM de la ccaAn.
\end{tabular}


El cuadro 2 presenta el análisis del subconjunto de peticiones que se relacionan con asuntos en materia de aguas residuales. Como se puede esperar, en materia de bosques, el mayor número de peticiones es contra Canadá (una nación típicamente forestal), lo cual no sorprende. Es interesante, sin embargo, darse cuenta de que existen al menos dos denuncias relacionadas con bosques en contra México. Es posible (hipotéticamente) que en mayor medida estas peticiones sean más bien el resultado de una lucha por los derechos de la población indígena con una vertiente colindante de relevancia en materia de bosques. Dadas las zonas geográficas de influencia, no resulta descabellada esta hipótesis.

\begin{tabular}{|lll|}
\hline \multicolumn{2}{|c|}{ Cuadro 3 } \\
PETICIONES CIUDADANAS DE 1996 A 2012 EN MATERIA DE BOSQUES \\
Nombre de petición & País & Área geográfica \\
Logging Rider & Estados Unidos & Alaska \\
Ortíz Martínez & México & Jalisco \\
BC Logging & Canadá & Columbia Británica \\
Tarahumara & México & Chihuahua \\
Ontario Logging & Canadá & Ontario \\
Ontario Logging II & Canadá & Ontario \\
$\begin{array}{l}\text { Fuente: Elaboración a partir de análisis propio de base de datos creada con información disponible } \\
\text { públicamente de la oficina del SEM de la ccaAn. }\end{array}$ \\
\hline
\end{tabular}

Si comparamos los cuadros 2 y 3, podemos ver que en el caso de bosques, el área de impacto geográfico está más delimitada, mientras que en aguas residuales, trasciende incluso fronteras (como muestra el caso de Devils Lake en la zona limítrofe entre Canadá y Estados Unidos). De nuevo, la prevalencia de Canadá como agente al cual se le presentan la mayoría de los casos es interesante y, vale la pena mencionarlo, ya que es sorprendente. De considerar válida la hipótesis del paraíso de contaminación (pollution heaven) se esperaría que la mayor parte de las peticiones fuera presentada contra México. Sin embargo, si bien de forma acumulada México sí es el líder, no es así cuando hacemos un análisis más fino y espacial.

En el caso de peticiones ciudadanas que tienen impacto o relación con aspectos de manejo de químicos, la distribución en cuanto a países es mucho más sesgada hacia México, lo cual probablemente no sorprende, dada la percepción generalizada de 
que Estados Unidos utiliza a México (o al menos así parece visualizarlo) como "el basurero en el patio trasero de Estados Unidos". Como muestra la gráfica 8, el 64 por ciento de las denuncias específicamente en materia de químicos se presentan en contra de México, el 6 por ciento en contra de Canadá y el 9 por ciento en contra de Estados Unidos.

\section{Gráfica 8}

DISTRIBUCIÓN DEL NÚMERO TOTAL DE DENUNCIAS CIUDADANAS SOBRE CUMPLIMIENTO AMBIENTAL (1996-2012) EN MATERIA DE QUÍMICOS ( $\mathrm{N}=22)$

Denuncias en materia de químicos (1995-2012)

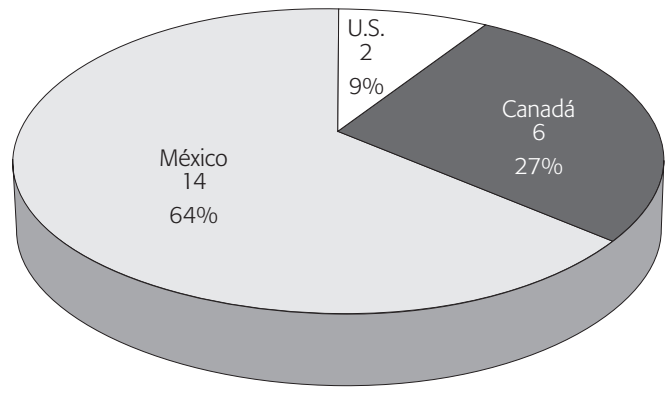

Fuente: Cálculos propios utilizando una base de datos construida con información disponible del SEM de la CCAAN.

En un análisis más fino en cuanto al área geográfica de influencia (véase el cuadro 4), podemos observar que los casos que motivan las denuncias en contra de Estados Unidos tienen afectación al menos en dos países, lo cual es preocupante. Esto quiere decir que a pesar de que México encara más demandas ciudadanas por asuntos relacionados con químicos, las denuncias que enfrenta Estados Unidos tienen un ámbito geográfico de impacto muy superior a las que enfrentan Canadá y México.

Estos resultados tienen gran relevancia dado el desinterés que muestran las ONGA estadunidenses por utilizar el mecanismo en contra de su propio país, y es desconcertante si se considera que precisamente las peticiones tienen como objeto minimizar los potenciales daños ambientales que generan los países en América del Norte. También, este análisis pone de relieve el hecho de que se debe hacer uso del mecanismo, ya que los asuntos en los cuales se está enfocando la CCAAN son de importancia y pueden tener impactos sustanciales negativos sobre la salud humana en Norteamérica. 


\section{Cuadro 4}

\section{PETICIONES CIUDADANAS DE 1996 A 2012 EN MATERIA DE QUÍMICOS}

\section{Nombre de la petición}

BC Mining

Great Lakes

Cytrar I

Metales y Derivados

Molymex I

Molymex II

AAA Packaging

Cytrar II

Dermet

Pulp and Paper

ALCA-Iztapalapa

Ontario Power Generation

ALCA-Iztapalapa II

Cytrar III

Quebec Automobiles

Coal-fired Power Plants

Residuos peligrosos en Arteaga

Ex Hacienda El Hospital

Ex Hacienda El Hospital II

Ex Hacienda El Hospital III

La Ciudadela

PCB Treatment in Grandes-Piles
País

Canadá

EU

México

México

México

México

Canadá

México

México

Canadá

México

Canadá

México

México

Canadá

EU

México

México

México

México

México

Canadá
Área geográfica

Columbia Británica

Al menos dos países

Sonora

Tijuana

Sonora

Sonora

Quebec

Sonora

Jalisco

Al menos dos países

Ciudad de México

Ontario

Ciudad de México

Sonora

Quebec

Al menos dos países

Coahuila

Morelos

Morelos

Morelos

Jalisco

Quebec

Fuente: Elaboración a partir de análisis propio de una base de datos creada con información disponible públicamente de la oficina del SEM de la CCAAN. 


\section{EVIDENCIA EMPÍRICA SOBRE EL FUNCIONAMIENTO DE LAS DENUNCIAS CIUDAdanas SOBRe CUMplimiento ambiental en AmÉRICA del NorTE}

Existe una gran variedad de perspectivas que critican el funcionamiento de las denuncias ciudadanas. Antes de proceder a discutir dichas perspectivas, presento datos cuantitativos sobre qué ha pasado con las denuncias a lo largo del tiempo. En primer lugar, es importante saber cuántas de las denuncias que se han presentado se han resuelto de manera satisfactoria para quienes las presentan (la gráfica 9).

\section{Gráfica 9}

COMPARACIÓN DEL NÚMERO DE DENUNCIAS CIUDADANAS SOBRE CUMPLIMIENTO AMBIENTAL (1996-2012) RESUELTAS CONTRA EL NÚMERO DE PETICIONES RECIBIDAS $(\mathrm{N}=81)$

Denuncias recibidas vs. resueltas

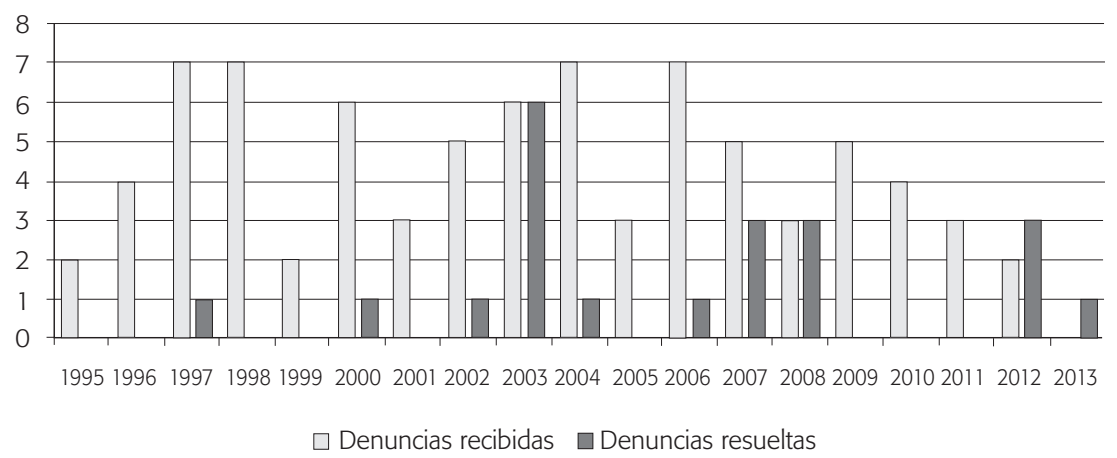

Fuente: Elaboración propia usando base de datos del SEM de la CCAAN.

El número de denuncias que se reciben es mucho mayor al de las que se solucionan; en promedio se reciben 4.5 denuncias contra 1.2 resueltas anualmente. Solamente se resuelve el 26 por ciento de las denuncias que se reciben. En este análisis se indica que las peticiones "se resuelven" cuando las denuncias crean un expediente de hechos y éste se da a conocer a la ciudadanía.

No todas las denuncias presentadas continúan con el proceso de desahogo de pruebas. Hay denuncias que la CCAAN indica que no ameritan continuar con el proceso. En la gráfica 10 se presenta un comparativo de cuántas denuncias se reciben contra cuántas justifican la continuación del proceso (en total). 


\section{Gráfica 10}

COMPARACIÓN DEL NÚMERO DE DENUNCIAS CIUDADANAS SOBRE CUMPLIMIENTO AMBIENTAL (1996-2012) QUE AMERITAN PROCESO CONTRA EL NÚMERO DE PETICIONES RECIBIDAS ( $\mathrm{N}=81)$

Denuncias recibidas vs. denuncias justificadas

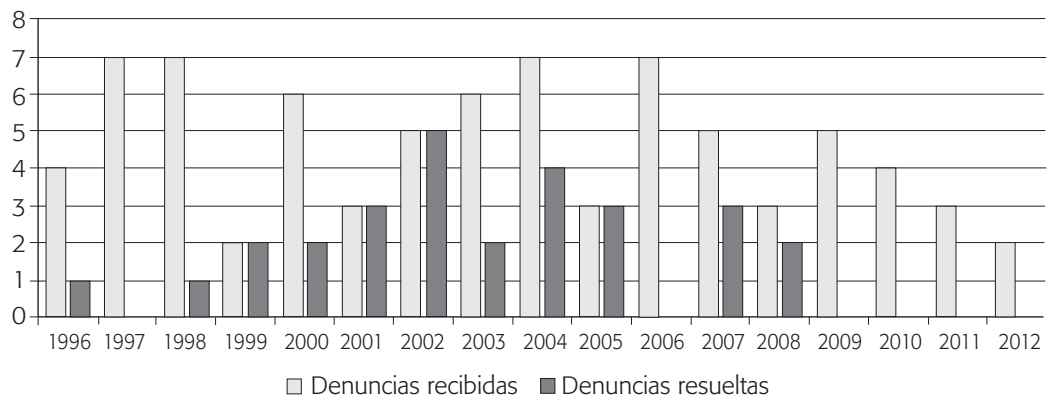

Fuente: Elaboración propia a partir de la base de datos del SEM de la CCAAN.

Las denuncias justificadas son aquellas que cumplieron con los criterios para proceder y que el Secretariado ha considerado que están correctamente justificadas. La mayoría de las veces éstas posteriormente dan lugar a la creación de un expediente de hechos que es presentado a la ciudadanía y terminan su proceso. El número de denuncias justificadas casi siempre es menor al número de denuncias recibidas la mayoría de los años. Solamente en 1999, 2001, 2002 y 2005 el número de denuncias recibidas y justificadas fueron iguales. Después de 2009 ninguna denuncia ha sido considerada como justificada, lo cual presenta un interesante dilema para cuestionar las razones por las cuales se considera que tales expedientes no ameritan continuar.

\section{Gráfica 11}

COMPARACIÓN DEL NÚMERO DE DENUNCIAS CIUDADANAS SOBRE CUMPLIMIENTO AMBIENTAL (1996-2012) QUE AMERITAN PROCESO CONTRA EL NÚMERO DE PETICIONES RECIBIDAS, SEGMENTADAS POR PAÍS $(\mathrm{N}=81)$

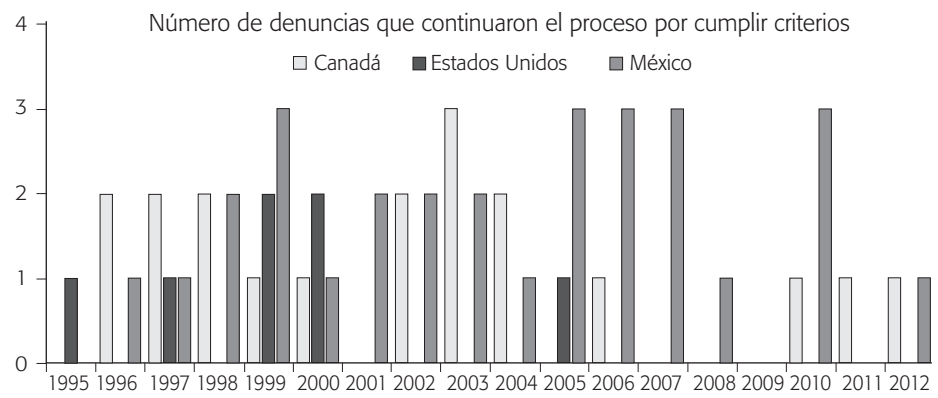

Fuente: Elaboración propia a partir de la base de datos del SEM de la CCAAN. 
México, como es el país contra el cual se ha presentado en total el mayor número, también es el país contra el cual se presenta el mayor número de denuncias que cumplen con los criterios para dar seguimiento a las mismas, como puede verse en la gráfica 7: promedia 1.6 denuncias por año apegadas a los criterios. La mayoría de los años los países difícilmente superan las dos denuncias que continúan con el proceso y nunca han sido más de tres. El que las denuncias cumplan con los criterios quiere decir que están apegadas a los artículos y requerimientos que pide la CCAAN para ser válidas. Algunas veces terminan en la creación de expedientes públicos para la sociedad y otras veces no terminan su proceso por decisión del Secretariado, de la comisión o de los mismos peticionarios. En la gráfica 12 presento la distribución de las razones por las cuales se cierra el proceso de la petición ciudadana, utilizando la base de datos creada para este fin.

\section{Gráfica 12}

NÚMERO DE DENUNCIAS TERMINADAS POR CADA UNA DE LAS RAZONES PRESENTADAS (1996-2012) $(\mathrm{N}=81)$

Razones por las que termina el proceso de denuncia ante la CCAAN

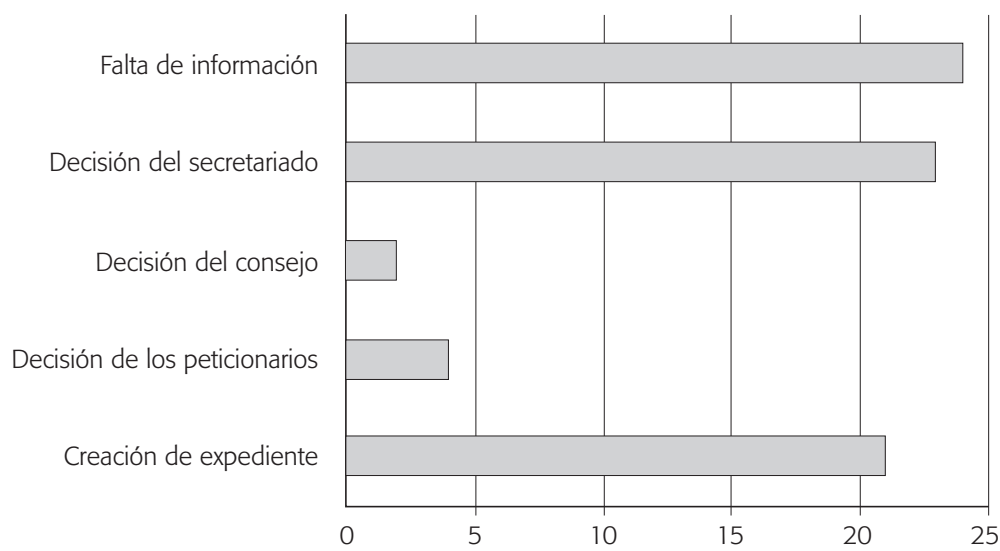

Fuente: Elaboración propia a partir de la base de datos del SEM de la CCAAN.

Los principales motivos por los que las denuncias finalizan su proceso son tres: falta de información (es decir, que el peticionario no presenta suficiente información acompañando su denuncia como para que el Secretariado tome una decisión); decisión del Secretariado (es decir, que presenta suficiente información para tomar una decisión con respecto a si continúa o no el proceso, pero el Secretariado considera 
que no tiene argumentos suficientemente robustos como para que el proceso siga); o la creación de expediente de hechos (que también es una razón para que el proceso termine, ya que es el fin último del proceso de peticiones ciudadanas). También puede darse una petición por terminada por decisión unilateral del Consejo o por la decisión de los peticionarios (es decir, cuando los solicitantes consideran que no es una buena idea continuar con el proceso o carecen de los recursos para hacerlo), aunque este fenómeno es poco común. El 30 por ciento de las denuncias finalizan su proceso por falta de información e incumplimiento de criterios, mientras que por decisión del Secretariado es el 28 por ciento y solamente el 26 por ciento termina el proceso satisfactoriamente. Esta última cifra es preocupante si se considera la inversión tanto en recursos humanos, como materiales y de tiempo, tanto por parte del Secretariado como de las partes (los países de América del Norte). Si solamente uno de cada cuatro expedientes presentados termina el proceso, es evidente que hay posibles fuentes de ineficiencia e ineficacia. La única forma de determinar si en realidad la emisión, presentación y difusión del expediente de hechos ha tenido impacto es analizar las acciones del gobierno del país en cuestión posteriormente a la fecha en la cual se presenta el expediente de hechos.

\section{Principales CRíticas al MECANISMO DE DENUNCIA CIUdAdANA Sobre CUMplimiento ambiental en América del Norte}

El mecanismo de denuncia ciudadana ha sido criticado y exaltado casi en medidas iguales. Dependiendo de quién clasifique las críticas, existen cuatro temáticas principales sobre las cuales se evalúa el mecanismo. El primer elemento de crítica es la falta de instrumentación vinculante. El proceso no tiene demandas como tal y, por ende, se considera que no tiene "dientes" (Lewis, 2007), esto es, un instrumento del derecho "suave" (Graubart, 2001) o soft law, mismo que no tiene naturaleza vinculante y por tanto no puede hacerse cumplir con la misma firmeza, ya que no existen agentes que puedan hacer uso de un fundamento canónico legal contra el cual establecer una sanción por el incumplimiento (Lewis, 2007). Blair confirma esta crítica al indicar el potencial de que los países definan cumplimiento de manera muy laxa (Blair, 2003).

El segundo elemento de crítica del mecanismo es la falta de implementación y monitoreo de los expedientes de hechos por las partes (Wold, 2004). De nada sirve que exista un mecanismo muy bonito de denuncias ciudadanas sin que realmente tenga algún proceso diseñado para verificar que los expedientes de hechos tengan un impacto específico sobre la forma en la cual se cumple (o no) la legislación ambiental en cada país. El tercer elemento de crítica es la injusticia inherente del proceso, tanto 
sustancial como procedimental. Como bien indican Markell y Knox (2012), tanto el diseño del proceso como la implementación demuestran que existe injusticia procedimental, en primera instancia porque los países tienen dobles papeles: son los "blancos" de las denuncias y, al mismo tiempo, mantienen un gran poder sobre cómo se lleva a cabo el proceso decisorio a lo largo de la trayectoria histórica de la denuncia.

Adicionalmente, es importante hacer notar que hay un cuarto elemento que constituye una de las críticas más agrias al proceso de las denuncias ciudadanas: es sumamente tardado, y conlleva un esfuerzo extraordinario para quienes participan en el mecanismo de presentar una petición ciudadana (Knox y Markell, 2012). En la evidencia cuantitativa presentada en el cuadro 5, se puede observar que de las diez denuncias activas contra cada país (de nuevo, domina el panorama México con el 50 por ciento de las denuncias), en promedio llevan 4.3 años en proceso. Esta duración es francamente excesiva y no motiva a los interesados a realmente continuar prestando atención a una denuncia cuando el tiempo transcurrido es superior a uno o dos años.

\section{Cuadro 5 \\ DENUNCIAS ACTIVAS CONTRA CADA PAÍS DE AMÉRICA DEL NORTE Y TIEMPO QUE ACTUALMENTE LLEVAN EN PROCESO}

$\begin{array}{lccl}\text { Título de la petición } & \text { Fecha de envío } & \text { Años } & \text { País } \\ \text { Centrales carboeléctricas } & 20 / 09 / 2004 & 8.47 & \text { EU } \\ \text { Contaminación ambiental en Hermosillo II } & 30 / 08 / 2005 & 7.53 & \text { México } \\ \text { Ex Hacienda El Hospital II } & 17 / 07 / 2006 & 6.65 & \text { México } \\ \text { Ex Hacienda El Hospital III } & 22 / 09 / 2006 & 6.46 & \text { México } \\ \text { Humedales en Manzanillo } & 04 / 02 / 2009 & 4.09 & \text { México } \\ \text { Estanques de residuos en Alberta } & 13 / 04 / 2010 & 2.90 & \text { Canadá } \\ \text { Tratamiento de aguas residuales en lona } & 07 / 05 / 2010 & 2.84 & \text { Canadá } \\ \text { Protección del oso polar } & 05 / 12 / 2011 & 1.26 & \text { Canadá } \\ \text { Cañón del Sumidero II } & 29 / 11 / 2011 & 1.27 & \text { México } \\ \text { Granjas de salmón de Columbia Británica } & 15 / 02 / 2012 & 1.06 & \text { Canadá } \\ \text { Parques eólicos del río San Lorenzo } & 14 / 12 / 2012 & 0.23 & \text { Canadá } \\ \text { Fuente: Elaboración propia con nuestra base de datos creada con información públicamente } \\ \text { disponible del sEm de la ccAan. En los casos de denuncias contra Estados Unidos y Canadá se } \\ \text { utilizan los nombres de los casos en español como se citan en el sitio web de la ccaAn. }\end{array}$


Una de las razones por las cuales existe un mecanismo de denuncias ciudadanas y que frecuentemente se olvida en las discusiones sobre el TLCAN y del ACA es que las organizaciones ambientalistas estadunidenses estaban preocupadas por que México se convirtiera de manera ya no virtual sino real en el basurero en el patio trasero de Estados Unidos. En realidad, en el proceso de las negociaciones del TLCAN, con el fin de obtener una aprobación del tratado, se agregaron las disposiciones ambientales en un acuerdo colateral que evitara la situación comúnmente denominada "el paraíso de los contaminadores" (pollution heaven). En realidad, se pretendía que este tratado diera herramientas y sentara bases para que pudiera incrementarse el cumplimiento de las leyes ambientales en México (Bailey, 2004; Behre, 2003), y promover la participación ciudadana como objetivo colateral (Aspinwall, 2013).

\section{CAMBIOS RECIENTES EN LA ESTRUCTURA DEL MECANISMO DE DENUNCIAS CIUDADANAS SOBRE CUMPLIMIENTO AMBIENTAL eN AMÉRICA del NorTE}

Si bien el mecanismo de peticiones ciudadanas ha sido objeto de reflexiones frecuentes, y existe un informe anterior denominado Lecciones aprendidas ${ }^{3}$ (Lessons learned), publicado el 6 de junio de 2001, más recientemente, el 7 de noviembre de 2011, ${ }^{4}$ el Secretariado de la CCAAN convino una serie de reuniones y talleres sobre el mecanismo, creó una Fuerza de Trabajo y emitió una serie de recomendaciones ${ }^{5}$ para cambiar las "Guías para la presentación de peticiones ciudadanas". Estas recomendaciones y los cambios a las guías fueron aprobados en la sesión del Consejo de la CCAAN el 11 de julio del $2012 .^{6}$

El objetivo de la Fuerza de Trabajo fue presentar recomendaciones sobre cómo debe mejorarse el mecanismo de denuncias ciudadanas. En los talleres, hubo algunos participantes que sugirieron cambios a los mecanismos de denuncia, y se supone que las denuncias presentadas después de publicadas las nuevas guías, en el verano de 2012, se adhieren ya a las mismas, en lugar de a los lineamientos anteriores. Entre los cambios relevantes que se añadieron al sistema, estuvo la inclusión de un límite de tiempo, como se aprecia en la gráfica 13.

\footnotetext{
${ }^{3}$ En http:/ / www.cec.org/Storage/40/3255_rep11-s-final_ES.PDF>.

${ }^{4}$ Minutas de la reunión en San Antonio, Texas, disponibles en <http:/ / www.cec.org/Page.asp?PageID=924 \&SiteNodeID=1030>.

${ }^{5}$ En <http:/ / www.cec.org/Storage/137/16238_JPAC_Advice_12-01-Final-en.pdf>.

${ }^{6}$ En <http: / / www.cec.org/Page.asp?PageID=122\&ContentID=25243\&SiteNodeID=1053\&BL_ExpandID>.
} 
Gráfica 13

DIAGRAMA DE FLUJO REVISADO DEL PROCESO DE DENUNCIA CIUDADANA

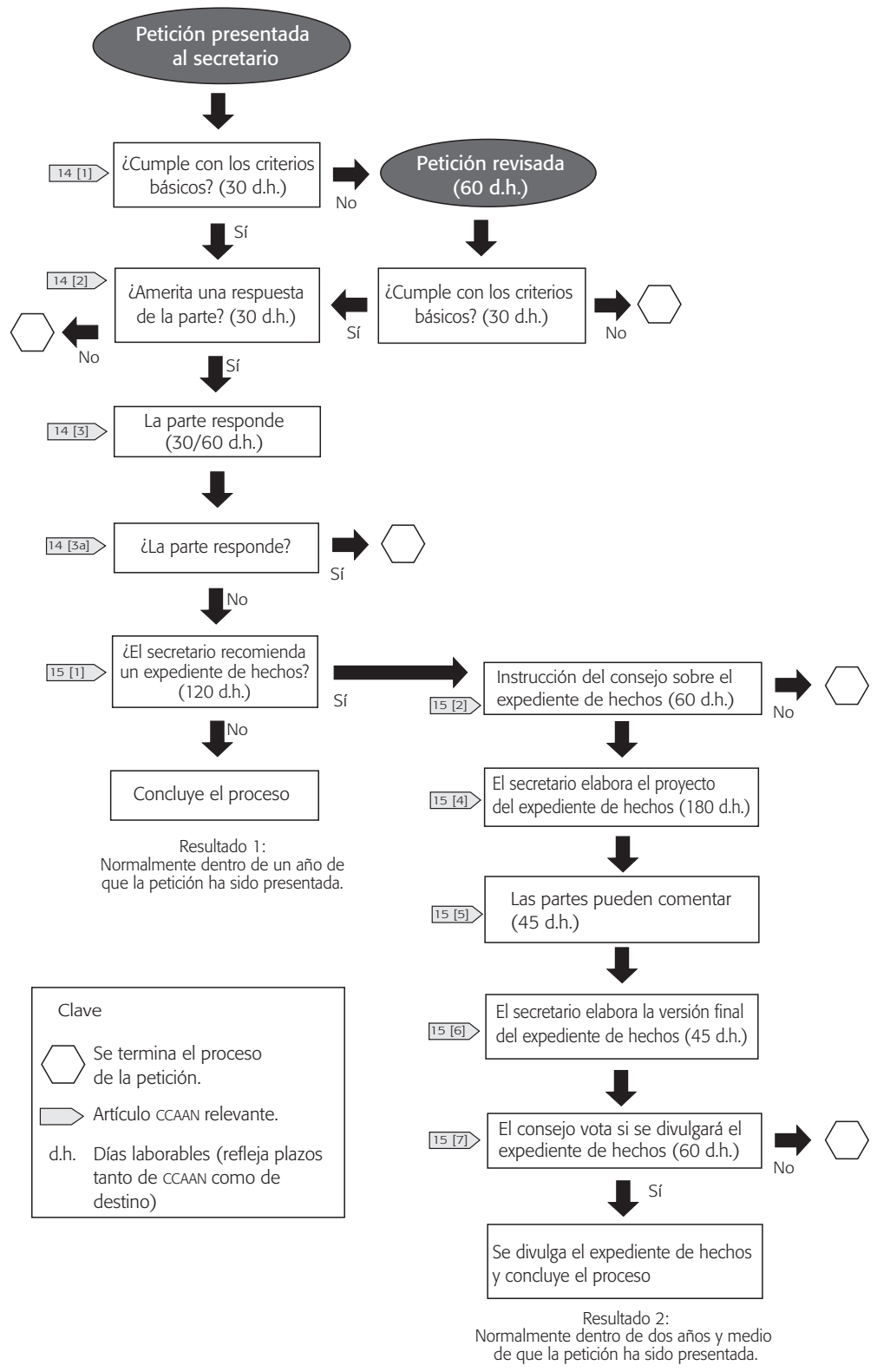

Fuente: Elaboración propia con base en el reporte de la CCAAN, julio de 2012. 
El Consejo del Comité Conjunto de la CCAAN (JPAC, por sus siglas en inglés) al Secretariado 12-01, del 12 de mayo del 2012, indicó que la Fuerza de Trabajo para la Modernización del SEM debería enfocarse en hacer el proceso más expedito, más accesible en incrementar la independencia del Secretariado y de sus recomendaciones y en desarrollar un seguimiento para los expedientes de hechos. Al analizar con detalle los nuevos lineamientos, es posible darse cuenta que la mayor parte de los cambios realizados a los mismos se enfocaron en establecer límites de tiempo, si bien el seguimiento sigue siendo relativamente vago. Por ello, es necesario hacer de nuevo una evaluación del mecanismo una vez que hayan transcurrido al menos entre dos y cinco años de la implantación de los nuevos lineamientos para la presentación de las peticiones.

\section{Conclusiones}

\section{El mecanismo de denuncias ciudadanas de la CCAAN como instrumento de política ambiental norteamericana en perspectiva}

El análisis del mecanismo de denuncias ciudadanas de la CCAAN como instrumento de política ambiental resulta más o menos complicado dependiendo de la perspectiva que se tome. Si el mecanismo tiene como resultado, en gran parte, el fortalecimiento de las redes transnacionales de activistas (como se demuestra en la sección sobre el alcance geográfico de las peticiones), y la formación de coaliciones de ONGA que intercambian información y recursos intelectuales, de tal suerte que se construyen capacidades a lo largo de América del Norte, entonces sí es un mecanismo exitoso. En gran medida, se considera exitoso precisamente porque el TLCAN y sus tratados en sí mismos tenían la intención de un diseño de tipo cooperativo (Studer Noguez, 2010), en el cual la colaboración entre organizaciones de la sociedad civil se viera fortalecida. Como se puede apreciar en las gráficas y cuadros presentados anteriormente, las peticiones presentadas por coaliciones transnacionales fueron también algunas de las llegaron más lejos en el proceso de la denuncia.

A manera de conclusión, he aquí algunas reflexiones en torno a cómo podría redireccionarse la agenda de investigación respecto al mecanismo de la denuncia ciudadana sobre cumplimiento ambiental de la CCAAN, que emanan colateralmente de la evidencia empírica presentada. Como se puede observar en los cuadros 1 a 4, poco se sabía sobre las razones inherentes que tienen las organizaciones de la sociedad civil para presentar denuncias. Dado el alto número de denuncias asociadas con químicos, impacto ambiental y aguas residuales, podemos deducir que el mecanismo se usa más cuando hay situaciones en las cuales la integridad de un ecosistema corre peligro. 
El diseño del mecanismo pretendía establecer una herramienta para fortalecer el cumplimiento de la legislación ambiental en los países de América del Norte. Sin embargo, explorar el proceso a través de una perspectiva de derechos humanos, como se hizo recientemente, se antoja interesante (y controversial). Entre las recomendaciones que se han propuesto para mejorar el mecanismo de denuncia ciudadana por incumplimiento de la legislación ambiental en América del Norte se encuentra la de fortalecer el mecanismo utilizando lecciones aprendidas del estudio de los derechos humanos (Brisbois et al., 2002). Es interesante que esta sugerencia, propuesta por Brisbois y colaboradores en el 2002, haya tenido eco en la CCAAN en el 2012, una década después, ya que recientemente se realizó un foro organizado en forma conjunta con la Comisión Nacional de Derechos Humanos en la Ciudad de México, donde se presentó la Sexta Visitaduría de la CNDH y se ligó al mecanismo de denuncias ciudadanas sobre cumplimiento ambiental de la CCAAN con el derecho humano al saneamiento, al agua y a un medio ambiente sano (que ya ha sido enmarcado en la Constitución Política de los Estados Unidos Mexicanos). Sin embargo, es de hacer notar que no es suficiente ligar ambos conceptos, sino que hay que establecer mecanismos para hacer valer dichos derechos.

La liga entre derecho humano a un medio ambiente sano y la posibilidad de hacer una denuncia ciudadana es vaga, y únicamente posible si se considera que entre los derechos inherentes al ser humano se encuentre el poder tener voz y voto en las decisiones de política pública que le afectan directamente (ya que la petición ciudadana puede verse como un mecanismo de participación de la ciudadanía) (Behre, 2003; Longiaru, 2008), si bien no es clara la forma en la cual un mecanismo que se origina en una institución supranacional e intergubernamental puede tener incidencia directa en la participación ciudadana en México (contrario a lo que argumentan tanto Longiaru como Behre).

A pesar de sus limitaciones, el mecanismo de la petición ciudadana sobre cumplimiento ambiental se considera todavía como uno de los mejores modelos para fortalecer la participación ciudadana, entendida ésta como la inclusión, aun si es parcial, en los procesos decisorios de la política ambiental en América del Norte (Behre, 2003; Grandbois y Auger Bouchard, 2011; Spaulding, 1995). Sin embargo, los críticos del mecanismo hacen patentes las fallas que tiene tanto el diseño del instrumento como la implantación en la escala interna (Graubart, 2009; Knox y Markell, 2012; Knox, 2010; Markell, 2004; Pacheco-Vega et al., 2010; Tollefson, 2002).

Si bien todavía no se puede considerar que exista un régimen de política ambiental norteamericano (Knox, 2010; Tollefson, 2002), sí es posible establecer que ya hay cierto nivel de convergencia, sobre todo en materia de política de instrumentos de diseminación de información (Harrison y Pacheco-Vega, 2003) y de manejo de residuos 
tóxicos (Pacheco-Vega, 2007). Por ejemplo, actualmente el Registro de Emisiones y Transferencia de Contaminantes (RETC) es igualmente obligatorio en México como lo es en Estados Unidos y Canadá (Wold, 2008). Por lo mismo, si bien es posible postular la hipótesis que el régimen de política en América del Norte se encuentra en ciernes, no existe la evidencia empírica suficiente para llegar a esta conclusión.

De la misma forma, si bien los resultados cuantitativos presentados en este artículo indican que el uso de las denuncias ciudadanas se encuentra a la baja, no es despreciable la forma en la cual las coaliciones ambientalistas han utilizado el mecanismo para fortalecerse y construir capacidades (Rabet, 2011). Al menos cuatro casos de los que han llegado a las etapas más tardías del proceso (es decir, las últimas etapas) han sido postulados por coaliciones transnacionales. Es importante hacer notar que fortalecer a la sociedad civil en la escala global no quiere decir que ya se haya construido una ciudadanía ambiental global (Pacheco-Vega, 2006), sino más bien que se está en procesos preliminares de construir una ciudadanía ambiental norteamericana. Asimismo, aquí cabe insertar el comentario de Marois en el sentido de que con la denuncia ciudadana, la CCAAN institucionaliza el desacuerdo social (Marois, 2009). Sin embargo, con todo y sus deficiencias, es innegable que el mecanismo de denuncia ciudadana por el cumplimiento ambiental en América del Norte tiene un gran potencial para un impacto positivo en la salud de los ecosistemas en los tres países norteamericanos, siempre y cuando haya voluntad política para implantarlo como debiera ser, y sobre todo, de forma no unilateral sino completamente trinacional.

\section{BibLiografía}

ANAYA, A.

2011 "Explaining High Levels of Transnational Pressure over Mexico: The Case of the Disappearances and Killings of Women in Ciudad Juárez", The International Journal of Human Rights, vol. 15, no. 3, pp. 339-358. DOI: 10.1080/ 13642980903315323.

2009a Altos niveles de presión transnacional sobre México por violaciones de derechos humanos: el caso de las desapariciones y asesinatos de mujeres en Ciudad Juárez. Mexico, CIDE (Documentos de Trabajo, 190).

2009b "Transnational and Domestic Processes in the Definition of Human Rights Policies in Mexico", Human Rights Quartely, vol. 31, no. 1, pp. 35-58. 
Aspinwall, M.

2013 Side Effects: Mexican Governance Under NAFTA's Labor and Environmental Agreements, Palo Alto, Calif., Stanford University Press.

BAILEY, K.M.

2004 "Citizen Participation in Environmental Enforcement in Mexico and the United States: A Comparative Study", The Georgetown International Environmental Law Review, vol. 16, no. 2, pp. 323-358.

BEHRE, C.N.

2003 "Mexican Environmental Law: Enforcement and Public Participation since the Signing of NAFTA's Environmental Cooperation Agreement", Journal of Transnational Law \& Policy, vol. 12, no. 2, pp. 327-343.

BLAIR, D.J.

2003 “The CEC's Citizen Submission Process: Still a Model for Reconciling Trade and the Environment?", The Journal of Environment \& Development, vol. 12, no. 3, pp. 295-324. DOI: $10.1177 / 1070496503255577$

BorRego Pérez, N.

2006 "Las políticas públicas de protección al ambiente en Norteamérica", Revista Mexicana de Estudios Canadienses, no. 011, verano, pp. 163-192.

Borrego, N., R. Cantú, J. Soto y M. Nava

2007 "Mecanismos de resolución de controversias entre comercio y medioambiente: ¿ligando agua y aceite?", Revista Mexicana de Estudios Canadienses, no. 014, pp. 119-144.

Brisbois, B., S. Diffenderferder, A. Fukuda, A. Ransom-Hodges, G. Pritchard y J. White 2002 "Improving the Commission for Environmental Cooperation's Submission Procedure: Recommendations Based on Human Rights Complaint Mechanisms" Montreal, QC, Canada, p. 47.

GIFUNI, L.

2011 “The CEC's Council Discretionary Decision Making under Article 15 of the NAAEC and Its Legality at International Law", Proceedings of the Meeting of the North American Consortium on Legal Education (NACLE). Comparative Environment Law Research Project, Montreal, North American Consortium on Legal Education. 
Grandbois, M. y M.-C. Auger Bouchard

2011 "Public Participation in Transnational Law: Access to Justice in Environmental Matters in North American Treaties", McQuarie Journal of International and Comparative Environmental Law, vol. 7, no. 1, pp. 1-21.

Graubart, J.

2009 "The Legalization of Transnational Political Opportunity Structures: Mobilization of NAFTA's Labor Citizen Petitions for Domestic Political Gain", en J.M. Ayres y L. Macdonald, eds., Contentious Politics in North America: National Protest and Transnational Collaboration under Continental Integration, Basingstoke, Palgrave Macmillan, pp. 177-194.

2005 "Politicizing a New Breed of 'Legalized' Transnational Political Opportunity Structures: Labor Activists Uses of NAFTA's Citizen-Petition Mechanism", Berkeley Journal of Employment \& Labor Law, vol. 26, no. 1, pp. 97-142.

2001 “Giving Meaning to New Trade-linked 'Soft Law' Agreements on Social Values: A Law-in-action Analysis of NAFTA's Environmental Side Agreement", UCLA Journal of International Law \& Foreign Affairs, vol. 6, pp. 425-462.

Harrison, K. y R. Pacheco-Vega

2003 "The Politics of Information Dissemination: International Institutions, Transnational Coalitions and Policy Change", Washington, D.C., Fall Conference of the American Public Policy and Management Association, American Public Policy and Management Association.

KIRTON, J.

2002 “NAFTA's Trade-Environment Regime and Its Commission for Environmental Cooperation: Contributions and Challenges Ten Years On", Canadian Journal of Regional Science, vol. 25, no. 2.

KNOx, J.H.

2010 "The Neglected Lessons of the NAFTA Environmental Regime", Wake Forest Law Review, vol. 45, pp. 101-134.

2004 "Separated at Birth: The North American Agreements on Labor and the Environment", Loyola of Los Angeles International \& Comparative Law Review, vol. 26, pp. 359-387. 
KNOx, J.H. y D.L. MARKELL

2012 "Evaluating Citizen Petition Procedures: Lessons from an Analysis of the NAFTA Environmental Commission", Texas International Law Journal, vol. 47, no. 3, pp. 505-540.

LEWIS, B.N.

2007 "Biting without Teeth: The Citizen Submission Process and Environmental Protection", University of Pennsylvania Law Review, vol. 155, no. 1229, pp. 1229-1268.

LONGIARU, M.

2008 "The Secondary Consequences of International Institutions: A Case Study of Mexican Civil Society Networks and Claims-making", California Western International Law Journal, vol. 37, pp. 63-120.

MARKELL, D.L.

2005 "Governance of International Institutions: A Review of the North American Commission for Environmental Cooperation's Citizen Submissions Process", North Carolina Journal of International Law and Commercial Regulation 30, 759-794.

2004 "The North American Commission for Envirommental Cooperation after Ten Years: Lessons about Institutional Structure and Public Participation in Governance", Loyola of Los Angeles International \& Comparative Law Review vol. 26, pp. 341-357.

MAROIS, T.

2009 "Un modelo neoliberal para institucionalizar el desacuerdo social: la Comisión de Cooperación Ambiental del TLCAN", Revista de El Colegio de San Luis, año X, no. 29, 57-66.

Nolan García, K.

2011 "The Evolution of United States-Mexico Labor Cooperation (1994-2009): Achievements and Challenges", Politics \& Policy 39, no. 1, 91-117. Dor: 10.1111/ j.1747-1346.2010.00284.x

OSOFSKY, H.M.

2006 "The Geography of the CEC's Citizen Submissions Process. Mapping the State-corporate Regulatory Dynamic", Michigan State Journal of International Law, vol. 14, pp. 463-478. 
Pacheco-Vega, R.

2007 “Mexico's Pollutant Release Registry: Taking Stock, Looking Ahead", en J. Fox et al., eds., Mexico's Right-To-Know Reforms: Civil Society Perspectives, Washington, D.C., pp. 270-275.

2006 “Ciudadanía ambiental global. Un recorte analítico para el estudio de la sociedad civil transnacional", Espiral: Estudios sobre Estado y Sociedad, vol. 12, no. 35, pp. 149-172.

2005 "Democracy by Proxy: Environmental NGos and Policy Change in Mexico", en A. Romero y S. West, eds., Environmental Issues in Latin America and the Caribbean, Dordrecht, Springer Verlag, pp. 231-249.

Pacheco-Vega, R. y H. Dowlatabadi

2005 "Environmental Regulation and Economic Spaces: The Mexican Leather and Footwear Industrial Districts", en R. LeHeron y J.W. Harrington, eds., New Economic Spaces, New Economic Geographies, Londres, Ashgate, pp. 154-164.

Pacheco-Vega, R., I. Weibust y J. Fox

2010 "Lessons from the Citizen Submissions on Enforcement Matters (CSEM) to the North American Commission on Environmental Cooperation (NACEC)", en Senderos de integración silenciosa en América del Norte, México, Programa Inter institucional de Estudios sobre la Región de América del Norte-El Colegio de México/Centro de Investigaciones sobre América del Norte (CISAN)-UnAM, pp. 173-205.

\section{Pacheco-Vega, R., M.C. Carmona-Lara y O. Vega-López}

2001 "The Challenge of Sustainable Development in Mexico", en P. Nemetz, ed., Bringing Business on Board: Sustainable Development and the B-School Curriculum, vol. 21, Vancouver, pp. 715-739.

Pacheco-Vega, R. y O. Vega

2003 “Cooperación internacional para la protección ambiental: la formación de coaliciones en perspectiva", Foro Internacional XLIII, no. 2, pp. 403-428.

POWELl, F.

2000 "The North American Commission for Environmental Cooperation's San Pedro Report: A Case Study and Analysis of the CEC Process", The Environmental Lawyer, vol. 6, pp. 809-838. 
RABET, D.

2011 "Libre comercio y gobernanza del medio ambiente en México: ¿complementariedad o contradicción?", Análisis, año 14, no. 40, pp. 91-118.

Raustiala, K.

2004 "Police Patrols \& Fire Alarms in the NAAEC", Loyola of Los Angeles International E Comparative Law Review, vol. 26, pp. 389-413.

\section{Secretariat of the Commission for Environmental Cooperation}

1993 North American Agreement on Environmental Cooperations, Montreal, Secretariat of the Commission for Environmental Cooperation, p. 40.

SPAULDING, M.J.

1995 "Transparency of Environmental Regulation and Public Participation in the Resolution of International Environmental Disputes", Santa Clara Law Review, vol. 35, pp. 1127-1142.

StANTON KiBel, P.

2001 "The Paper Tiger Awakens: North American Environmental Law After the Cozumel Reef Case", Columbia Journal of Transnational Law, vol. 395, pp. 395-482.

StUder Noguez, M.I.

2010 "The NAFTA Side Agreements: Toward a More Cooperative Approach?", Wake Forest Law Review, vol. 45, pp. 469-490.

TOLLEFSON, CHRIS

2002 "Games Without Frontiers: Investor Claims and Citizen Submissions Under the NAFTA Regime", The Yale Journal of International Law, vol. 27, pp. 141-191.

TORRES, B.

2005 "Transnational Actors and NAFTA: The Search for Coalitions on Labor and the Environment", en L. Fawcett y M. Serrano, eds., Regionalism and Governance in the Americas/Continental Drift, Londres, Palgrave Macmillan.

2002 "The North American Agreement on Environmental Cooperation: Rowing Upstream", en C.L. Deere y D.C. Esty, eds., Greening the Americas: NAFTA's Lessons for Hemispheric Trade, Cambridge, Mass., The MIT Press.

1999 “Las ONG ambientalistas en las relaciones México-Estados Unidos", Foro Internacional, vol. 39, no. 4, pp. 453-478. 
WiLsON, S.

2005 "NAFTA's Legacy: An Explanation of Why the Free Trade Area of the Americas Is Good for International Environmental Law", Temple Journal of Science, Technology and Environmental Law, vol. 24, no. 2, pp. 551-583.

Wold, C.

2008 "Evaluating NAFTA and the Commission for Environmental Cooperation: Lessons for Integrating Trade and Environment in Free Trade Agreements", Saint Louis University Public Law Review, vol. 28, pp. 201-252.

2004 "The Inadequacy of the Citizen Submission Process of Articles 14 \& 15 of the North American Agreement on Environmental Cooperation", Loyola of Los Angeles International \& Comparative Law Review, vol. 26, pp. 415-444.

YANG, $\mathrm{T}$.

2005 "The Effectiveness of the NAFTA Environmental Side Agreement's Citizen Submission Process: A Case Study of the Metales y Derivados Matter", University of Colorado Law Review, vol. 76, no. 2, pp. 443-502. 